\title{
Electrical anisotropy of gas hydrate-bearing sand reservoirs in the Gulf of Mexico
}

\author{
Ann E. Cook ${ }^{\mathrm{a}, *}$, Barbara I. Anderson ${ }^{\mathrm{b}}$, John Rasmus ${ }^{\mathrm{c}}$, Keli Sun ${ }^{\mathrm{c}}$, Qiming $\mathrm{Li}^{\mathrm{c}}$, \\ Timothy S. Collett ${ }^{\mathrm{d}}$, David S. Goldberg ${ }^{\mathrm{e}}$ \\ ${ }^{a}$ National Research Council/National Energy Technology Laboratory, Methane Hydrate Postdoctoral Fellow at Lamont-Doherty Earth Observatory, 61 Rt. 9 W, Palisades, \\ NY 10964, USA \\ ${ }^{\mathrm{b}}$ Consultant, Brookfield, CT, USA \\ ' Schlumberger, Sugar Land, TX, USA \\ ${ }^{\mathrm{d}}$ US Geological Survey, Denver, CO, USA \\ e Lamont-Doherty Earth Observatory, Palisades, NY, USA
}

\section{A R T I C L E I N F}

\section{Article history:}

Received 16 June 2011

Received in revised form

6 September 2011

Accepted 7 September 2011

Available online $\mathrm{xxx}$

\section{Keywords:}

Gas hydrate saturation

Electrical anisotropy

Sand reservoirs

Gulf of Mexico

\begin{abstract}
A B S T R A C T
We present new results and interpretations of the electrical anisotropy and reservoir architecture in gas hydrate-bearing sands using logging data collected during the Gulf of Mexico Gas Hydrate Joint Industry Project Leg II. We focus specifically on sand reservoirs in Hole Alaminos Canyon 21 A (AC21-A), Hole Green Canyon 955 H (GC955-H) and Hole Walker Ridge 313 H (WR313-H). Using a new logging-whiledrilling directional resistivity tool and a one-dimensional inversion developed by Schlumberger, we resolve the resistivity of the current flowing parallel to the bedding, $R_{\|}$and the resistivity of the current flowing perpendicular to the bedding, $R_{\perp}$. We find the sand reservoir in Hole AC21-A to be relatively isotropic, with $R_{\|}$and $R_{\perp}$ values close to $2 \Omega \mathrm{m}$. In contrast, the gas hydrate-bearing sand reservoirs in Holes GC955-H and WR313-H are highly anisotropic. In these reservoirs, $R_{\|}$is between 2 and $30 \Omega \mathrm{m}$, and $R_{\perp}$ is generally an order of magnitude higher.

Using Schlumberger's WebMI models, we were able to replicate multiple resistivity measurements and determine the formation resistivity the gas hydrate-bearing sand reservoir in Hole WR313-H. The results showed that gas hydrate saturations within a single reservoir unit are highly variable. For example, the sand units in Hole WR313-H contain thin layers (on the order of $10-100 \mathrm{~cm}$ ) with varying gas hydrate saturations between 15 and $95 \%$. Our combined modeling results clearly indicate that the gas hydratebearing sand reservoirs in Holes GC955-H and WR313-H are highly anisotropic due to varying saturations of gas hydrate forming in thin layers within larger sand units.
\end{abstract}

(c) 2011 Elsevier Ltd. All rights reserved.

\section{Introduction}

Natural gas hydrate is an electrical insulator, and thus resists the flow of electric charge (Pearson et al., 1983). This characteristic of natural gas hydrate has been frequently used to assess the amount of gas hydrate in the sediment pore space, $\varphi$, using well logging tools that measure either resistivity or conductivity (e.g. Collett and EhligEconomides, 1983; Hyndman et al., 1999; Collett and Ladd, 2000; Collett, 2001; Malinverno et al., 2008), with the premise that the higher the measured resistivity, the larger the amount of electrical insulator (in this case, gas hydrate) occupying the pore space. This assumption, based on Archie's formulation, quantifies the amount of electrical insulator in the pore space using the ratio of the resistivity

\footnotetext{
* Corresponding author. Tel.: +1 845365 8796; fax: +1 8453653182 .

E-mail address: acook@ldeo.columbia.edu (A.E. Cook).
}

of water-saturated sediment, $R_{0}$, to the measured resistivity, $R_{\mathrm{t}}$. In this paper, we employ the simplified Archie quick look equation to calculate gas hydrate saturation, $S_{\mathrm{h}}$ :

$S_{\mathrm{h}}=1-\left(\frac{R_{\mathrm{o}}}{R_{\mathrm{t}}}\right)^{1 / n}$

that involves estimating $R_{\mathrm{O}}$ (Archie, 1942). The saturation exponent, $n$, calibrates the ratio of $R_{\mathrm{o}}$ to $R_{\mathrm{t}}$. Further descriptions of the application of Archie's equation in gas hydrate environments can be read in the list of references above.

The measured resistivity, however, is not solely dependent on the amount of hydrate occupying the pore space. In shallow marine environments, changes in pore water salinity can greatly affect the measured resistivity (e.g., Pearson et al., 1986; Hyndman et al., 1999). In addition, the hydrate morphology can significantly affect the measured resistivity (Spangenberg, 2001). Another significant 
factor controlling the measured resistivity is the orientation of the resistivity measurement with respect to the formation bedding planes, particularly when the bedding planes are thinner than the resolution of the measurement.

Consider the thin-layered cube shown in Figure 1, which is similar to layers of flat-lying sediment. For the purpose of this example, we assume the gray, water-saturated layers have a resistivity, $R_{\mathrm{WL}}$, of $1 \Omega \mathrm{m}$, and the white, gas hydrate-filled layers have a resistivity, $R_{\mathrm{HL}}$, of $150 \Omega \mathrm{m}$. Half of the cube volume is filled with the water-saturated layers, $V_{\mathrm{WL}}$, and the other half of the cube is filled with the hydrate-saturated layers $\left(1-V_{\mathrm{WL}}\right)$. If electrodes are placed on opposite ends of the cube as marked with the red arrows, the current flows parallel to the layers, $R_{\|}$, and may be represented by the harmonic mean:

$R_{\|}=\left(\frac{V_{\mathrm{WL}}}{R_{\mathrm{WL}}}+\frac{\left(1-V_{\mathrm{WL}}\right)}{R_{\mathrm{HL}}}\right)^{-1}$

Using the prescribed resistivity values above, $R_{\|}$for the cube is approximately $2 \Omega \mathrm{m}$. In contrast, if the electrodes are placed at opposite ends of the cube as marked with the blue arrows, the current flows perpendicular to the layers, $R_{\perp} . R_{\perp}$ may be calculated using the arithmetic mean:

$R_{\perp}=V_{\mathrm{WL}} R_{\mathrm{WL}}+\left(1-V_{\mathrm{WL}}\right) R_{\mathrm{HL}}$

$R_{\perp}$ for the cube is approximately $76 \Omega \mathrm{m}$. Clearly, the direction resistivity is measured across the cube strongly influences the measured resistivity value. When the measured resistivity depends on the direction of the measurement, electrical anisotropy is present.

Electrical anisotropy as related to logging measurements, as well as Equations (2) and (3), are well documented in the literature (e.g. Anderson et al., 1994; Lüling et al., 1994; Klein et al., 1997; Anderson, 2001; Kennedy et al., 2001). Most logging tools that measure formation resistivity (or conductivity) chiefly measure the change in current or electromagnetic waves in the formation normal to the borehole wall. Thus, in a vertical hole with flat-lying sediments, most logging tools respond primarily to the resistivity parallel to the bedding planes, or $R_{\|}$which is dominated by the lower resistivity beds. If sediments are thinly layered and have

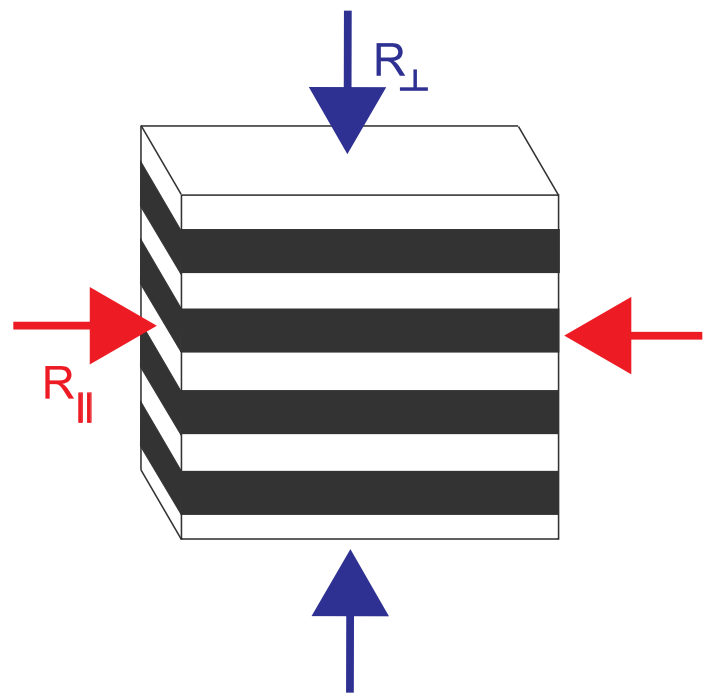

Figure 1. An idealized reservoir composed of thin layers of water-saturated sediment (gray) and hydrate-saturated sediment (white). Electrodes placed on the ends of the cube marked with red arrows measure the current flowing parallel to layers, $R_{\|}$ (Equation (2)). Electrodes placed on the ends of the cube marked with blue arrows measure the current flowing perpendicular to the layers, $R_{\perp}$ (Equation (3)). (For interpretation of the references to colour in this figure legend, the reader is referred to the web version of this article.) dramatically different resistivities, such as in Figure 1 example, the resistivity of the higher resistivity beds does not substantially influence the measurement. If the resistivities of thin, gas hydratefilled beds are underestimated, so is the amount of gas hydrate in the pore space (Equation (1)).

The PeriScope ${ }^{1}$ logging-while-drilling (LWD) tool was added to the Gulf of Mexico Gas Hydrate Joint Industry Project Leg II (JIP Leg II) bottom-hole assembly to help assess the electrical anisotropy of gas hydrate reservoirs (Mrozewski et al., 2010). Unlike most resistivity logging tools, the PeriScope collects a number of transverse and axial directional electromagnetic measurements that contain information about $R_{\|}, R_{\perp}$, formation dip and azimuth (Li et al., 2005; Sun et al., 2010). A $1 \mathrm{D}$ inversion developed by Schlumberger assumes a layercake formation model to resolve $R_{\|}$and $R_{\perp}$, formation dip and azimuth from PeriScope measurements (Sun et al., 2010). In this paper, we present new results from this inversion of the PeriScope measurements collected during JIP Leg II, with focus on relatively flatlying sand reservoirs at three sites in the Gulf of Mexico. We also conduct additional modeling for one reservoir to determine the formation resistivity, which improves estimates of hydrate saturation.

\section{Locations}

JIP Leg II drilled at seven locations and three sites in the Gulf of Mexico with LWD tools, exploring for gas hydrate in reservoir sands (Boswell et al., in this volume-a, in this volume-b; Collett et al., in this volume). Significant accumulations of gas hydrate in sand sediment were discovered at two of these Gulf of Mexico sites: Green Canyon Block 955, GC955, (McConnell et al., 2010a) and Walker Ridge Block 313, WR313 (McConnell et al., 2010b). At the third site, Alaminos Canyon Block 21, AC21, it is not clear from the LWD geophysical logs if gas hydrate or other factors caused slightly elevated resistivity in the sand interval (Frye et al., 2010).

At all three sites, JIP Leg II holes were drilled vertically. In addition, the sand reservoirs in all holes are relatively flat-lying. The most significant sand formation dip occurs at Site WR313, where the sand reservoir layers dip up to $25^{\circ}$. Electromagnetic logging measurements have only a slight response to $R_{\perp}$ in anisotropic formations at dip angles less than $30^{\circ}$, but have an increasing sensitivity to $R_{\perp}$ when layers dip above $50-60^{\circ}$ (e.g. Anderson, 1986; Lüling et al., 1994; Anderson, 2001; Ellis and Singer, 2007). In all JIP Leg II sand reservoirs, we consider the anisotropy due to formation dip to be negligible. In addition, no gas hydrate-filled fractures or nodules that could contribute to electrical anisotropy and affect formation resistivity are visible on the LWD image logs in the JIP Leg II sand reservoirs.

Changes in pore water salinity could also affect the measured resistivity and electrical anisotropy. While large changes in pore water salinity can occur in the Gulf of Mexico due to the presence of large salt bodies, Hanor and Mercer (2010) found that shallow sedimentary sections in the Gulf of Mexico generally contain normal seawater salinities. Exact pore water salinity is difficult to determine without direct measurement of salinity content in recovered core. Because cores were not collected at any of the JIP Leg II sites, we assume, for the purposes of modeling and interpretation in this paper, that pore water salinity is constant at a normal shallow sediment pore water concentration of $35 \mathrm{ppt}$.

\section{Inversion results}

Figures 2-4 display the results of the inversion for the gas hydrate-filled reservoir sands for Holes GC955-H, WR313-H and

\footnotetext{
1 Mark of Schlumberger.
} 
Hole GCC955-H
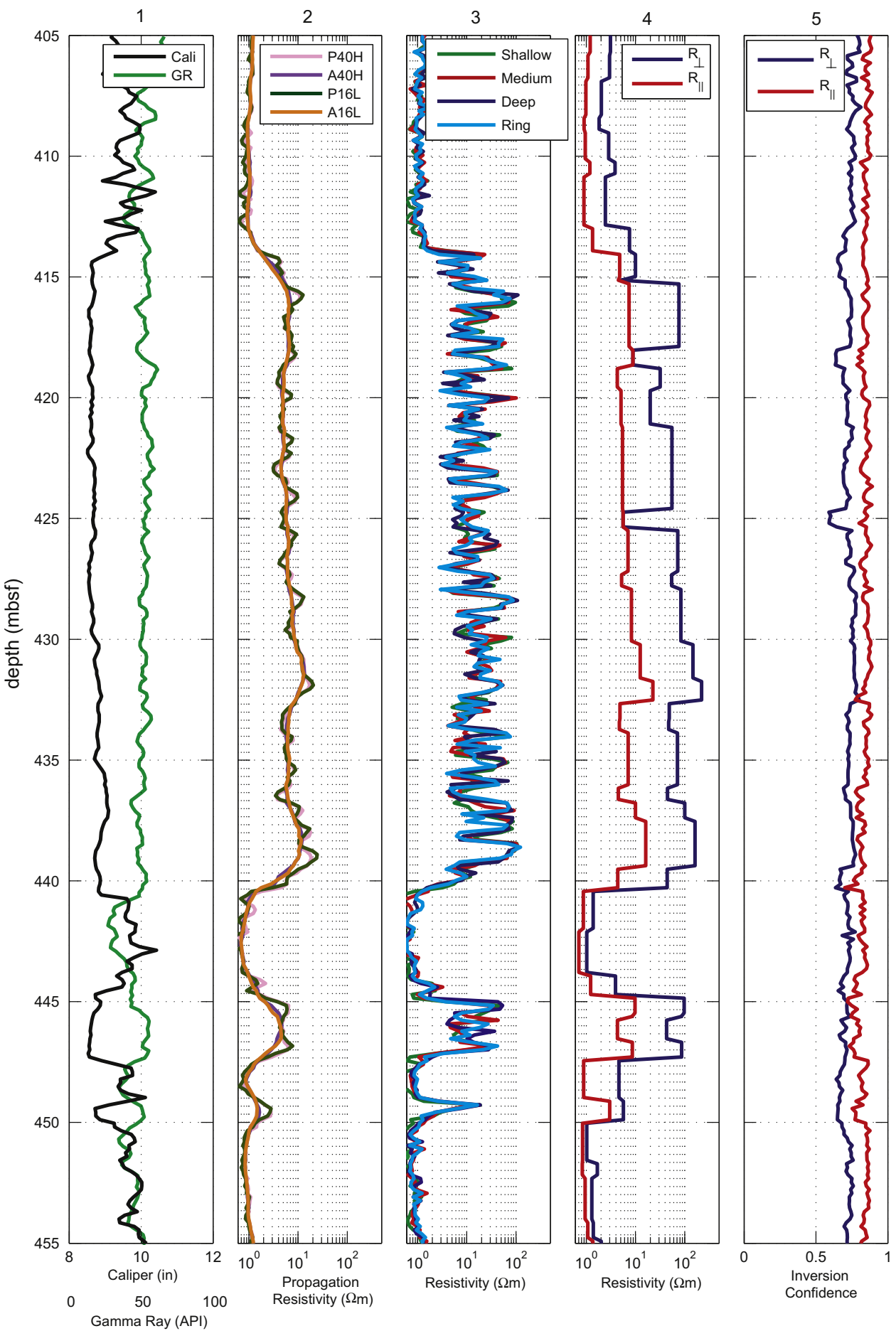

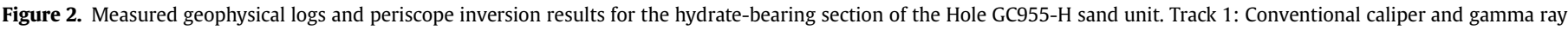

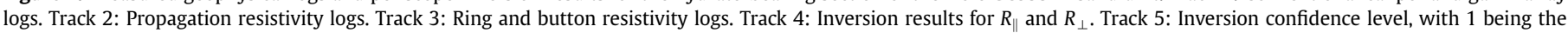
highest confidence.

AC21-A. We also present several measured logs from each hole to explain the borehole conditions, lithology, and presence of hydrate. Track 1 displays the caliper log, which describes the shape of the borehole wall. Borehole enlargements resulting in standoffs greater than 1-2 inches may degrade the quality of some other logging measurements collected in that zone. The gamma ray log also appears on Track 1; the log shows the natural gamma radiation of the sediments surrounding the borehole. In these shallow marine environments, low gamma radiation typically indicates sand sediment, while higher API values indicate clay sediments. In the JIP Leg II holes, the gamma ray tool has a vertical resolution of about $45 \mathrm{~cm}$ (Mrozewski et al., 2010). 


\section{Hole WR313-H}
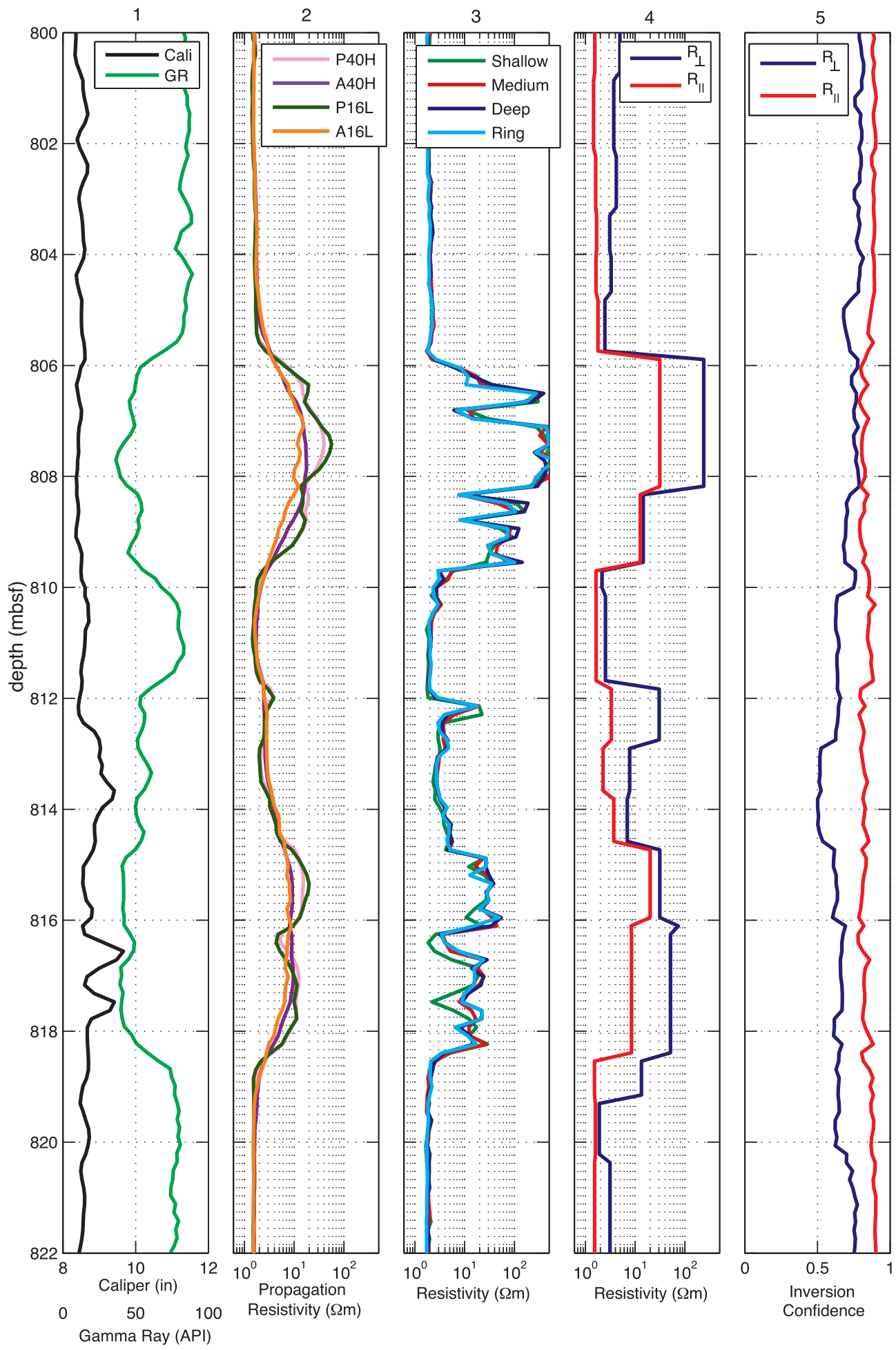

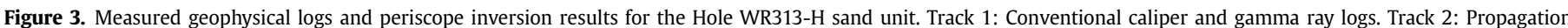
resistivity logs. Track 3: Ring and button resistivity logs. Track 4: Inversion results for $R_{\|}$and $R_{\perp}$. Track 5: Inversion confidence level, with 1 being the highest confidence.

Track 2 in Figures 2-4 displays a selection of propagation resistivity logs that encompass the maximum and minimum measured values. Propagation resistivity tools measure the change in phase (P) and attenuation (A) of an electromagnetic wave to determine formation resistivity. Measurements are made at $2 \mathrm{MHz}(\mathrm{H})$ and $400 \mathrm{kHz}(\mathrm{L})$ frequencies and at a variety of source and receiver spacings ranging from 16 to $40 \mathrm{in.}$ All of the variables that describe the particular log measurement are used in its heading in each figure track. For example, the $\mathrm{A} 40 \mathrm{H} \log$ is a $2 \mathrm{MHz}$ attenuation $\log$ with source and receiver spacing of 40 in. Propagation measurements penetrate deeply into the formation, between 0.5 and $1.5 \mathrm{~m}$, depending on the 
Hole AC21-A
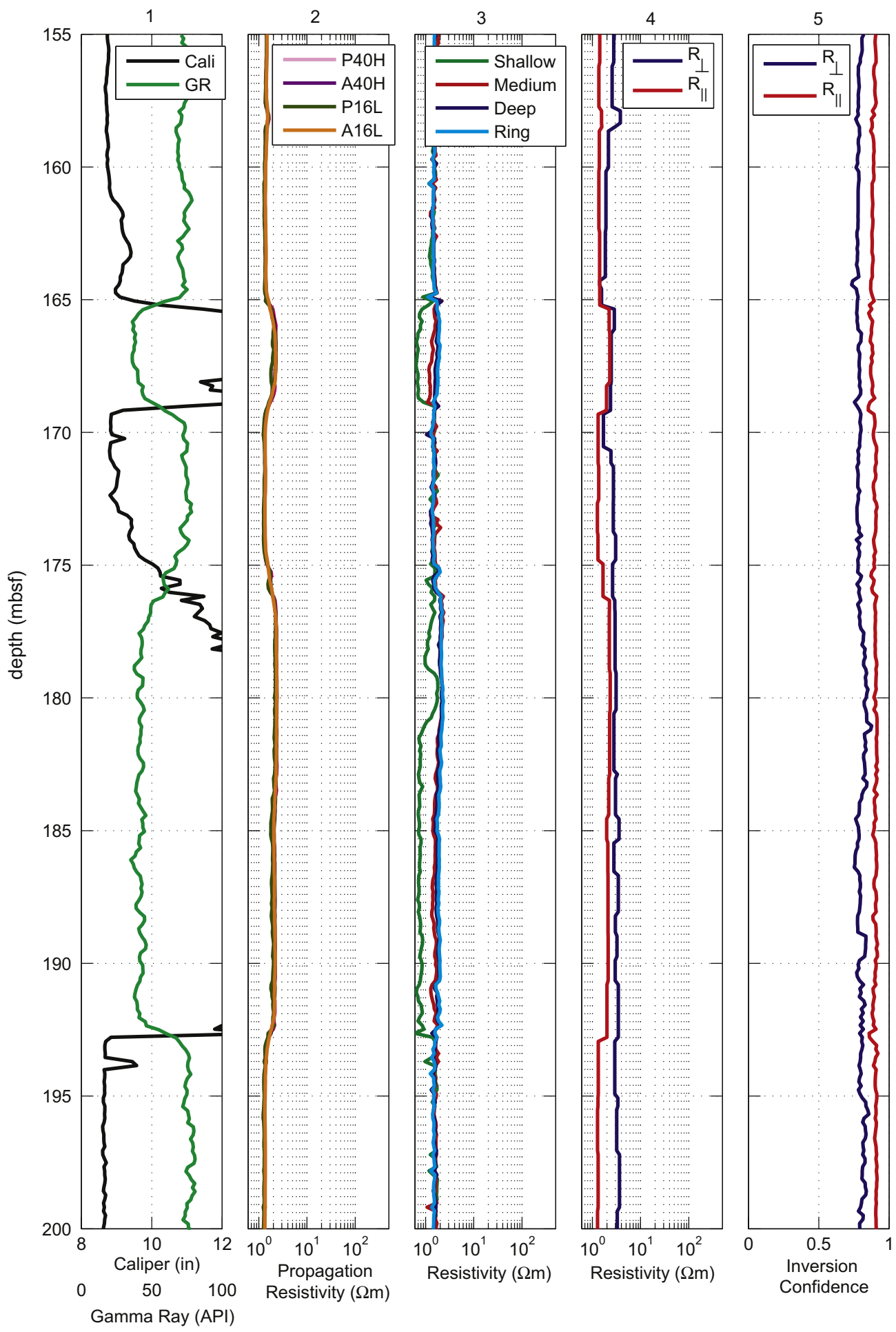

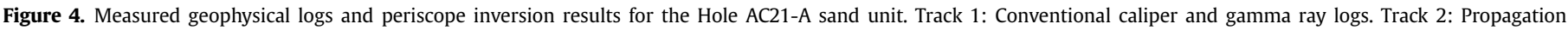
resistivity logs. Track 3: Ring and button resistivity logs. Track 4: Inversion results for $R_{\|}$and $R_{\perp}$. Track 5: Inversion confidence level, with 1 being the highest confidence.

measurement frequency and source and receiver spacing (Mrozewski et al., 2010). The vertical resolution of the propagation resistivity measurements is between 50 and $180 \mathrm{~cm}$ for attenuation resistivity measurements and $20-30 \mathrm{~cm}$ for phase resistivity measurements depending on the formation resistivity (Mrozewski et al., 2010).
Button and ring resistivity measurements appear on Track 3 in Figures $2-4$. These electrode type measurements have a much finer vertical resolution (about $7 \mathrm{~cm}$ ) than the propagation resistivity measurements (Schlumberger, 2006; Mrozewski et al., 2010). The shallow, medium, deep and ring resistivity measurements measure a resistivity volume relatively close to the borehole wall, 
penetrating into the formation, on average, about $3 \mathrm{~cm}, 8 \mathrm{~cm}, 13 \mathrm{~cm}$ and $17 \mathrm{~cm}$, respectively.

On Track 4 of Figures $2-4$, we report the $R_{\|}$and $R_{\perp}$ values resolved from the inversion. The vertical resolution and depth of penetration into the formation is similar to the propagation resistivity measurements. However, unlike the propagation resistivity measurements, there are measurements both parallel and perpendicular to the sediment layers. The presence of thin, high-resistivity layers is detected, but the actual boundaries of the very thin individual layers are not resolved as they are with the button and ring resistivity measurements.

On Track 5 of each figure, the inversion confidence is presented on a scale from 0 to 1 , with 1 being excellent confidence (Sun et al., 2010). Very thin layers, small-scale anisotropy, poor borehole conditions, highly dipping formations, and/or very high-resistivity values can all contribute to low inversion confidence (Sun et al., 2010). Along with $R_{\|}$and $R_{\perp}$, dip and azimuth are also resolved during the inversion process. Dip and azimuth, however, are not particularly informative in the relatively flat-lying sand reservoirs from JIP Leg II and are not reported in this paper.

\subsection{Site GC955}

Three holes were drilled in a late Pleistocene channel/levee just off the southeastern edge of the Sigsbee escarpment in Green Canyon Block 955 in the Gulf of Mexico (McConnell et al., 2010a; Boswell et al., in this volume-a, in this volume-b). The water depth in this area is about $2 \mathrm{~km}$. In Hole GC955-H, the sand appears from 390 to 490 mbsf (meters below seafloor). Gas hydrate occurs in parts of the sand unit in Hole GC955-H: a thick section between 413.5 and 440.5 mbsf, a small section between 445 and 447 mbsf and a thin bed near $449.5 \mathrm{mbsf}$. The total gross thickness of hydrate in sand in Hole GC955-H is $29 \mathrm{~m}$ (Collett et al., in this volume). In Figure 2, the sections of the log containing gas hydrate show an ingauge borehole (caliper log is close to the 8.5 -in bit size), suggesting the logging measurements are of good quality in those sections. Figure 2 also displays the results of the inversion for Hole GC955-H, originally presented in Sun et al. (2010). In the hydrate-bearing sand, $R_{\|}$values range between 4 and $20 \Omega \mathrm{m} . R_{\perp}$ is approximately an order of magnitude higher in the hydrate-bearing sand, with values spanning from 20 to $220 \Omega \mathrm{m}$. The inversion confidence for $R_{\|}$and $R_{\perp}$ is both high, suggesting accuracy in these inversion results.

The hydrate-bearing sand occurs in the middle of the Hole GC955-H sand unit and is surrounded by water-saturated sand. In the water-saturated sand, $R_{\|}$values between 0.7 and $1.2 \Omega \mathrm{m}$ and $R_{\perp}$ is typically $1-2 \Omega \mathrm{m}$ greater than $R_{\|}$. A small difference between $R_{\|}$and $R_{\perp}$ is expected due to slight anisotropy caused by microanisotropy of grain orientations as well as thin horizontally deposited layers (Sun et al., 2010). Despite the hole being enlarged $\sim 1$ inch in the water-saturated sand, the inversion confidence is robust; this result is unsurprising, as all of the propagation and button resistivity values in the water-saturated sands are very similar. Because the deeply penetrating propagation resistivity logs are effectively equal to the shallower button resistivity logs, this indicates that the enlarged borehole did not affect the resistivity measurements in the water-saturated sand.

In other holes drilled in Green Canyon, the PeriScope tool either did not log the sand reservoir or very little gas hydrate was encountered in the hole (Collett et al., in this volume). Therefore, the data from these holes are not presented in this paper.

\subsection{Site $W R 313$}

Gas hydrate was thought to occur in several dipping sand layers at Gulf of Mexico Walker Ridge Block 313 because the seismic sections of the area show high amplitude dim-outs (McConnell and Kendall, 2003) a phase reversals (McConnell and Zhang, 2005) in sand layers above and below the base of gas hydrate stability. Drilling at JIP Leg II Site WR313 validated that gas hydrate occurs in the sand layers.

Figure 3 shows the gas hydrate-bearing sand layer, the measured resistivity logs and the PeriScope inversion results for Hole WR313-H. The gamma ray log indicates two sand layers occurring between 805.5 and 810 mbsf and between 811.5 and $818.5 \mathrm{mbsf}$, for a total gross thickness of $11.5 \mathrm{~m}$ of hydrate-bearing sediment (Collett et al., in this volume). In the clay-rich sediment surrounding this sand layer, $R_{\|}$values are slightly less than $2 \Omega \mathrm{m}$, and $R_{\perp}$ ranges from 2 to $3 \Omega \mathrm{m}$. In the hydrate-bearing sands, $R_{\|}$ ranges from 2 to $30 \Omega \mathrm{m}$, and $R_{\perp}$ ranges from 7 to $240 \Omega \mathrm{m}$. The lowest values for $R_{\perp}$ coincide with the lowest value of confidence (0.5), suggesting that $R_{\perp}$ may be inaccurate and potentially higher in this interval.

At Site WR313, Hole WR313-G also penetrated gas hydratebearing sand layers, however, due to problems with acquisition of the PeriScope logs, $R_{\|}$and $R_{\perp}$ were not able to be resolved.

\subsection{Site $A C 21$}

Holes AC21-A and AC21-B were drilled in $\sim 1500 \mathrm{~m}$ of water in Alaminos Canyon Block 21, penetrating an extensive shallow sand layer (Frye et al., 2010). A study incorporating Hole AC21-B LWD data and regional seismic suggests that some moderate saturation $(\sim 20 \%)$ is present in the Site AC21 sand layer (Lee et al., in this volume). However, neither the geophysical logs collected in Hole $\mathrm{AC} 21-\mathrm{A}$ and $\mathrm{AC} 21-\mathrm{B}$ nor the analysis presented here is able to demonstrate that gas hydrate occurs in the sand layer.

In Hole AC21-A (Fig. 4), the sand layer can be clearly seen in two sections, from 165 to $169 \mathrm{mbsf}$ and from 175 to $192 \mathrm{mbsf}$, for a total gross sand thickness of $31 \mathrm{~m}$ (Collett et al., in this volume). The ring resistivity in the sand $(1.7-2.2 \Omega \mathrm{m})$, however, is only slightly higher than the resistivity in the surrounding clay $(1.3-1.5 \Omega \mathrm{m})$. The slightly higher resistivity may be due to low gas hydrate saturation, or due to other factors, such as decrease in porosity or a decrease in pore water salinity in the sand reservoir.

If gas hydrate is present in the AC21 sand, it is not present in sufficient quantities to cement the sand grains together. This is evident on the caliper log, which indicates the borehole is significantly enlarged from the $\sim 8.5$ in bit size, meaning the sand near the borehole has collapsed and sediment was washed away by drilling fluids. In general, borehole enlargements resulting in 1-2 inches of standoff can degrade the quality and accuracy of some LWD measurements. Typically, however, borehole enlargements do not greatly affect resistivity measurements. In Hole AC21-A, the shallow button resistivity log (in dark green in Fig. 4) appears to be the only resistivity measurement significantly affected by the borehole condition; the shallow resistivity log in the sand drops to $0.5 \Omega \mathrm{m}$, while the other resistivity logs read closer to $2 \Omega \mathrm{m}$. The resistivity falls because the shallow log is now measuring mostly borehole fluid, which has a resistivity of $\sim 0.4 \Omega \mathrm{m}$. The medium button may also be slightly affected by the borehole enlargement. By and large, however, the deep button resistivity, ring resistivity, and all of the propagation resistivity logs measured similar resistivity values for the sand layers, suggesting these deeper measurements were not compromised by the borehole enlargement.

Due to the minimal effect of the enlarged borehole on the propagation measurements, the inversion confidence is high for both $R_{\|}$and $R_{\perp}$ in the sands and the surrounding clay sediments. The high inversion confidence can be attributed to the low range of measured resistivity values, the negligible difference between $R_{\|}$ and $R_{\perp}$, and the general robustness of propagation resistivity 
measurements in enlarged holes. Values resolved for $R_{\|}$are almost identical to the ring resistivity, with $R_{\|}$ranging from 1.7 to $2.2 \Omega \mathrm{m}$ in the sand and $1.3-1.5 \Omega \mathrm{m}$ in the surrounding clay sediments. Thus, the measured ring resistivity effectively equals $R_{\|}$in Hole AC21-A. Values for $R_{\perp}$ are only slightly higher than $R_{\|} ; R_{\perp}$ values are between 2.4 and $3.4 \Omega \mathrm{m}$ in the sand and are between 1.4 and $3.8 \Omega \mathrm{m}$ in the surrounding clay sediments. The similarity of the resolved resistivity values from the inversion for $R_{\|}$and $R_{\perp}$ shows the sands are relatively isotropic.

The sand layer in Hole AC21-B is also isotropic and has similar measured resistivity, $R_{\|}$and $R_{\perp}$ values in the sand layer as Hole AC21-A. Because of the similarity, the results are not reported in this paper.

\section{Discussion}

There is a striking difference in the results of the PeriScope inversion in the sand intervals in Holes WR313-H and GC955-H, where gas hydrate occurs in high saturations, when compared with the inversion results in Hole AC21-A, where it is unclear if gas hydrate occurs. In Holes WR313-H and GC955-H there is a significant separation between $R_{\|}$and $R_{\perp}$. Whereas, in Hole AC21-A, the resistivity values in the sand are effectively isotropic. Isotropic or nearly isotropic resistivity is expected in water-saturated flat-lying sand or unconsolidated clay sediments. Small differences between $R_{\|}$and $R_{\perp}$ in these sediments are typically caused by slight variations in sediment content or grain orientation of the horizontally deposited layers. If gas hydrate indeed occurs in the sand unit at Site AC21, is occurs relatively homogenously and at very low concentrations in the pore space.

In contrast, the strong anisotropy in the sand units in Holes WR313-H and GC955-H must be caused by other factors, such as the presence of gas hydrate.

\subsection{Formation of hydrate in thin layers}

In Holes WR313-H and GC955-H the large separation between $R_{\|}$ and $R_{\perp}$ suggests that gas hydrate forms in thin layers within thick sand units. Ring resistivity and button resistivity measurements in both Holes WR313-H and GC955-H support this interpretation (Figs. 2 and 3). The high-resolution ring resistivity and button resistivity logs recorded thin high-resistivity layers, which vary in thickness from about 7 to $100 \mathrm{~cm}$. The vertical resolution of the ring and button resistivity measurements is about $7 \mathrm{~cm}$ (Schlumberger, 2006), which is probably less than the minimum thickness of most of the observed layers.

No thin layers are evident in the gamma ray logs within hydrate-bearing sands in Holes WR313-H and GC955-H (Figs. 2 and 3). The term "sand" is used to describe the hydrate-bearing sediments in both Holes WR313-H and GC955-H because the sediment has a lower natural radiation than other sediments in the hole, and thus is considered to have less clay content. Thin layers of sand alternating with thin layers of clay may be occur but remain well below the log resolution (about $45 \mathrm{~cm}$ ) and contribute to the stratification of hydrate saturation and the significant anisotropy. An alternative interpretation is that these sediments are composed entirely of sand grains, but form in layers with variable grain sizes and grain sorting. Thin layers with different grain size typically cause variations in permeability and capillary pressure that, in turn, affect both the migration of gas and the formation and quantity of gas hydrate (Clennell et al., 1999; Kleinberg et al., 2003; Nimblett and Ruppel, 2003; Seol and Kneafsey, 2009). Both interpretations - thin water-saturated clay interbedded with thin hydrate-saturated sand layers or thin sand layers with variable hydrate saturation-could cause the observed $R_{\|} / R_{\perp}$ anisotropy. In the following sections we will discuss our rationale for concluding that the latter case is the correct interpretation.

\subsection{The 'best' resistivity}

Considerable discussion persists about values for Archie parameters $a, m$ and $n$, which are used to calculate the resistivity of watersaturated sediment and hydrate saturation (e.g. Pearson et al., 1983; Spangenberg, 2001; Malinverno et al., 2008; Santamarina and Ruppel, 2008). These parameters can greatly affect the calculated hydrate saturation. In this analysis, however, we consider the significance of "true resistivity" or $R_{\mathrm{t}}$ in Equation (1). In practical terms, $R_{\mathrm{t}}$ does not necessarily equal any one of the measured formation resistivities because different resistivity measurements using different

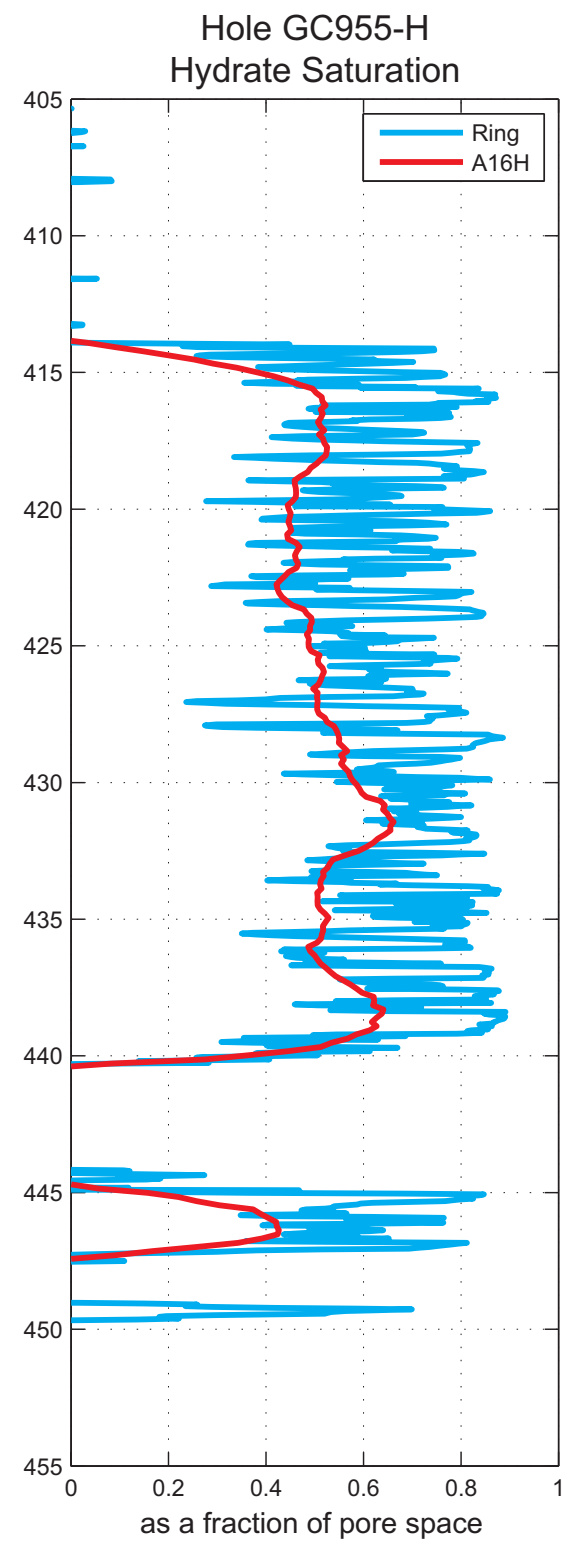

Figure 5. Gas hydrate saturation calculated using Archie's quick look method (Equation (1)) in Hole GC955-H using the A16L resistivity log (blue curve) and the ring resistivity log (red curve) for $R_{\mathrm{t}}$. Depth in meters below seafloor (vertical axis). (For interpretation of the references to colour in this figure legend, the reader is referred to the web version of this article.) 
sensors record significantly different resistivity values, as is clearly shown in Figures 2 and 3.

For petroleum exploration, low-frequency attenuation resistivity is often used for $R_{\mathrm{t}}$, such as the $\mathrm{A} 16 \mathrm{~L} \log$, for example, because it penetrates deep into the formation (up to $1.5 \mathrm{~m}$ ) and is minimally affected by borehole rugosity and/or the invasion of drilling fluids. Invasion of conductive or resistive drilling fluids into a permeable formation can dramatically alter the resistivity measurements, but neither Holes WR313-H or GC955-H show the characteristic separation of propagation resistivity and/or button resistivity curves that would be suggestive of this effect (e.g. Anderson, 2001; Ellis and Singer, 2007). Furthermore, the intervals in these wells that contain hydrate-bearing sands exhibit smooth and in-gauge boreholes, nearly equal to the 8.5-in. bit size (see Figs. 2 and 3). Therefore, it is unlikely that the measured resistivity logs are affected by either invasion or borehole shape in the hydrate-bearing sand

\section{Hole WR313-H}

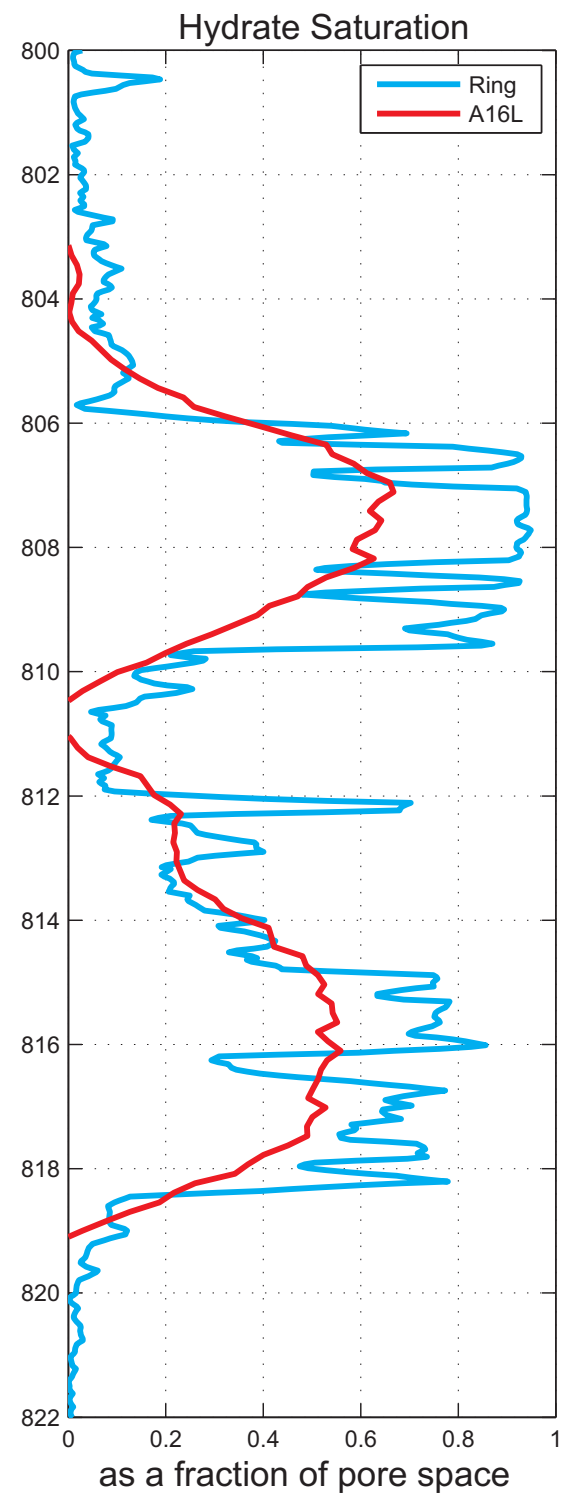

Figure 6. Gas hydrate saturation calculated using Archie's quick look method (Equation (1)) in Hole WR313-H using the A16L resistivity log (blue curve) and the ring resistivity log (red curve) for $R_{\mathrm{t}}$. Depth in meters below seafloor (vertical axis). (For interpretation of the references to colour in this figure legend, the reader is referred to the web version of this article.) intervals in Holes WR313-H and GC955-H. In these sands, the presence of hydrate most likely restricted permeability and drilling fluid invasion as it strengthened the formation and reduced spalling of the borehole walls.

In Figures 2 and 3, we observe that the average of the propagation resistivity measurements is effectively equal to $R_{\|}$. That result is expected in an environment with flat-lying or gently dipping layers that are below the resolution of the propagation resistivity measurement (Sun et al., 2010). The propagation resistivity logs in the sand units are dominated by the resistivity of the more conductive layers, similar to the $R_{\|}$measurement in the cube model (Fig. 1).

The ring resistivity measurement is often used to represent $R_{\mathrm{t}}$ in gas hydrate environments because it has the finest vertical resolution for its depth of investigation (Malinverno et al., 2008; Mrozewski et al., 2010). In Holes WR313-H and GC955-H, the ring resistivity is nearly equal to the button measurements and resolves
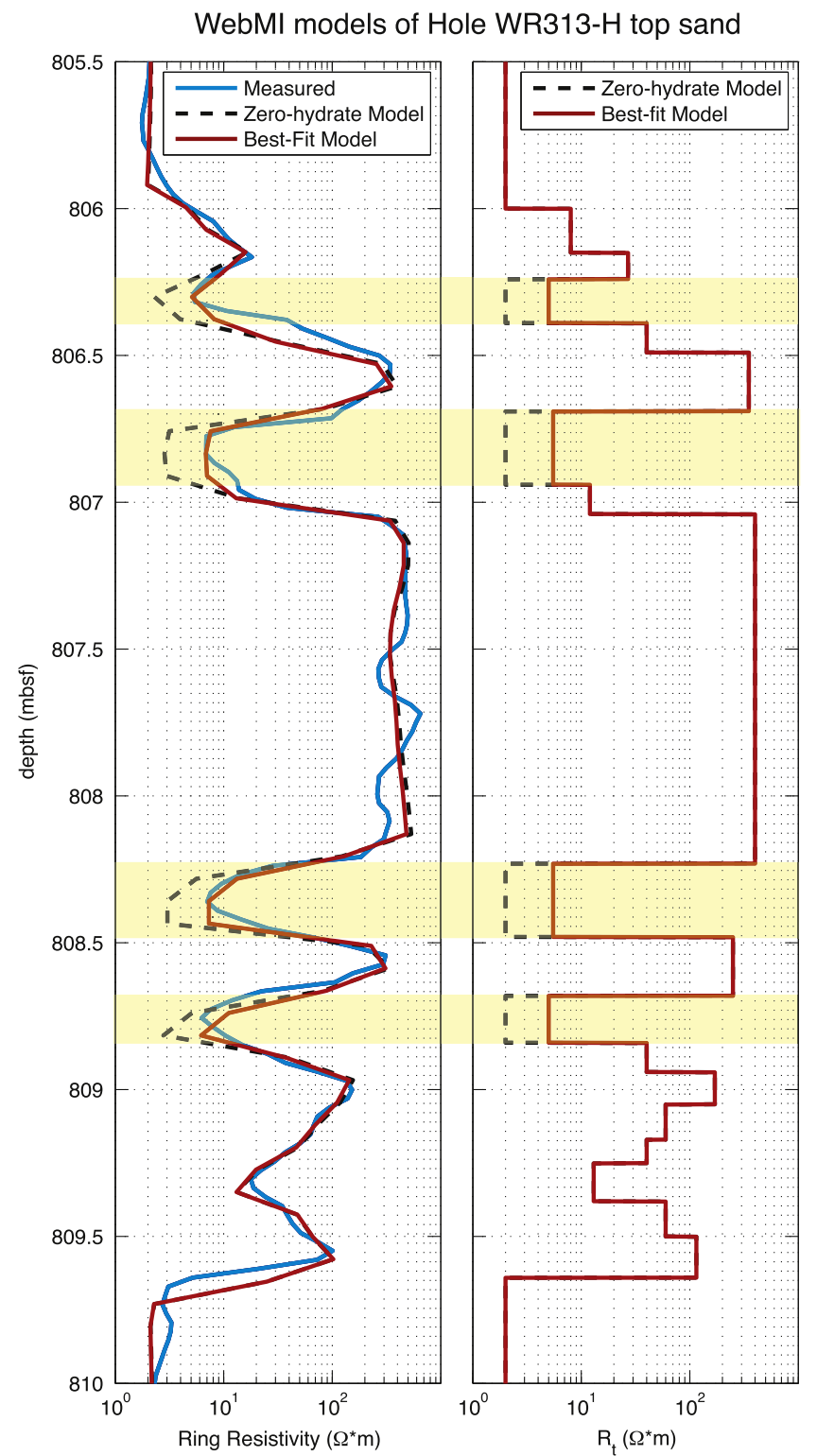

Figure 7. The first track shows the measured ring resistivity logs as well as the generated best-fit and zero-hydrate (control) model ring resistivity logs for the top sand section in Hole WR313-H. The second track shows the input formation model (effectively, $R_{\mathrm{t}}$ ) for the best-fit model and the zero-hydrate model. Depth in meters below seafloor (vertical axis). 
highly resistive layers with thicknesses, on average, between 7 and $100 \mathrm{~cm}$. The ring and button resistivity $\operatorname{logs}$ fall between $R_{\perp}$ on the high end and $R_{\|}$on the low end, as expected because of the thin layering in Holes GC955-H and WR313-H (Sun et al., 2010).

Figures 5 and 6 show calculated gas hydrate saturation from the Archie quick look method (Equation (1)) using ring resistivity and the $\mathrm{A} 16 \mathrm{~L}$ resistivity $\log$ for $R_{\mathrm{t}}$ in both holes. We use a constant value of $R_{\mathrm{O}}=1.5 \Omega \mathrm{m}$ for both holes. This assumed $R_{\mathrm{o}}$ corresponds to a water-saturated sand with approximately $36 \%$ porosity and a pore water salinity of about 35 parts per thousand. The value $n=2$ was used for the saturation exponent. The calculated gas hydrate saturations reflect the original logging measurements, as the ring saturation resolves thin layers with high hydrate saturation and the A16L saturation suggests gas hydrate occurs at lower saturations in thicker units.

Within the hydrate-bearing sand sections in Holes GC955-H and WR313-H, among all of the measured resistivity logs, the use of the ring resistivity log in Archie's equation best resolves the thin hydrate-filled layers. In all cases, however, if we knew the resistivity and porosity of the individual layers, we could compute the most accurate hydrate saturations.

\subsection{Determining $R_{t}$}

In Figure 1, we introduced an idealized cube model with thin water-saturated layers alternating with thin hydrate-saturated layers. In Holes WR313-H and GC955-H, the sand intervals could be just like the cube - thin layers with high hydrate saturation interbedded with exclusively water-saturated layers. In Figures 5 and 6 , many of the thin sand layers have significant hydrate saturation, ranging from 60 to $85 \%$. Alternating between the layers with high hydrate saturation are thin layers (generally less than $25 \mathrm{~cm}$ thick) that have ring resistivity values between 2 and $7 \Omega \mathrm{m}$. These layers have more moderate calculated hydrate saturations, typically between 15 and 60\%. These layers could either be fully water-saturated or contain moderate saturations of gas hydrate. In the first case, the ring resistivities of $2-7 \Omega \mathrm{m}$ are entirely a result of the convolved tool response or volume averaging, sometimes referred to as "shoulder bed" effects. In the second case, the lowresistivity layers do contain gas hydrate, but likely have a gas hydrate saturation somewhat lower than that calculated using Archie's formulation due to volume averaging.

If we were confident that the low-resistivity layers were exclusively water-saturated, or had constant resistivity values and hydrate content, we could use Equations (2) and (3) along with an estimated $V_{\mathrm{WL}}$ to determine the $R_{\mathrm{HL}}$; this technique is called laminated-sand analysis (Hagiwara, 1997; Klein et al., 1997). This approach is not applicable, however, if we cannot be confident values for $R_{\mathrm{WL}}$ are constant.

As an alternative method to determine the true formation resistivity for each layer in Holes WR313-H and GC955-H, we utilize Schlumberger's WebMI tool response codes (Polyakov et al., 2004, 2007, 2009). WebMI replicates the response of the LWD geoVISION ${ }^{1}$ Resistivity Tool (which collects the ring and button resistivity logs) as well as the LWD EcoScope ${ }^{1}$ Tool (which collects the propagation resistivity logs) based on an estimated input formation. The WebMI generated logs have similar vertical resolutions to the corresponding logging measurement.

For simplicity, we select the top sand section in Hole WR313-H from 805.5 to 810 mbsf to be representative of the an interbedded

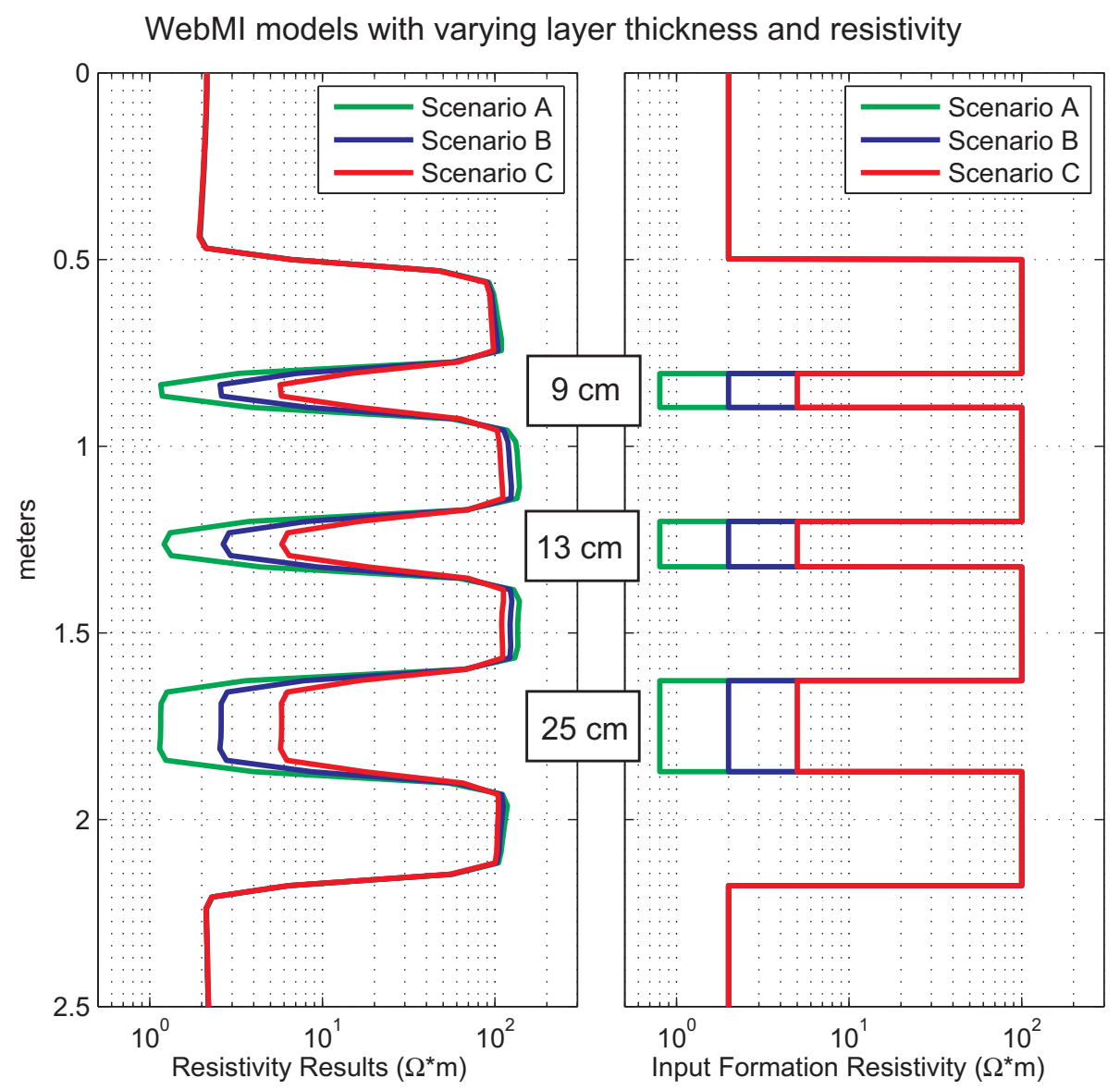

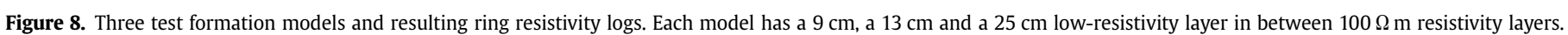


gas hydrate interval. This section of Hole WR313-H has the highest recorded ring resistivity values in the hydrate-saturated layers - so any effect of volume averaging or shoulder bed effects in the lowresistivity layers should be most pronounced in this section.

To determine initial resistivity values for $R_{\mathrm{WL}}$ and $R_{\mathrm{HL}}$, we use $R_{\|}$, $R_{\perp}$ and an estimated volume as input for Equations (2) and (3). We then formulated a formation model of the Hole WR313 sand reservoir using the initial resistivity values and estimated layer thicknesses. We ran the intial formation model in WebMI for a 6.75in size drill collar and borehole mud resistivity of $0.4 \Omega \mathrm{m}$.

After obtaining the results of the formation model and comparing it to the measured geophysical logs, we adjust the layer thicknesses and resistivity and input the adjusted formation model. We continued to use iterative-forward modeling to obtain the best-fit $R_{\mathrm{t}}$ for the top sand section in Hole WR313-H. This systematic approach to determine a best-fit $R_{\mathrm{t}}$ has been used for decades to better understand the influence of specific environmental conditions or measurement effects on a variety of resistivity logs (Anderson, 1986, 2001; Anderson et al., 1989). During our model iterations, we especially focused on determining the best-fit $R_{\mathrm{t}}$ for the low-resistivity layers, as shown in Figure 7 with yellow shading.

Figure 7 shows best-fit formation $R_{\mathrm{t}}$, the model ring resistivity from WebMI and the measured ring resistivity for the top sand in Hole WR313-H; the measured and modeled logs do not exactly match, but in general, the logs are very similar. The best-fit $R_{\mathrm{t}}$ shows some layers have abrupt resistivity boundaries while other layers have more gradational changes in resistivity. Very thin beds below the resolution of the ring resistivity $\log$ (thinner than $7 \mathrm{~cm}$ ) as well as other heterogeneities within each layer are averaged in log resistivity measurements and cannot be accurately included in the forward model. Most importantly, however, observed resistivity values in the low-resistivity beds are replicated almost exactly by the best-fit model results.

The best-fit $R_{\mathrm{t}}$ for the high-resistivity layers range from 15 to $400 \Omega \mathrm{m}$. On the previous calculation of hydrate saturation for Hole WR313-H (Fig. 6), there was no question that these layers contained gas hydrate. Do the low-resistivity layers (highlighted in yellow) contain gas hydrate? The best-fit formation model

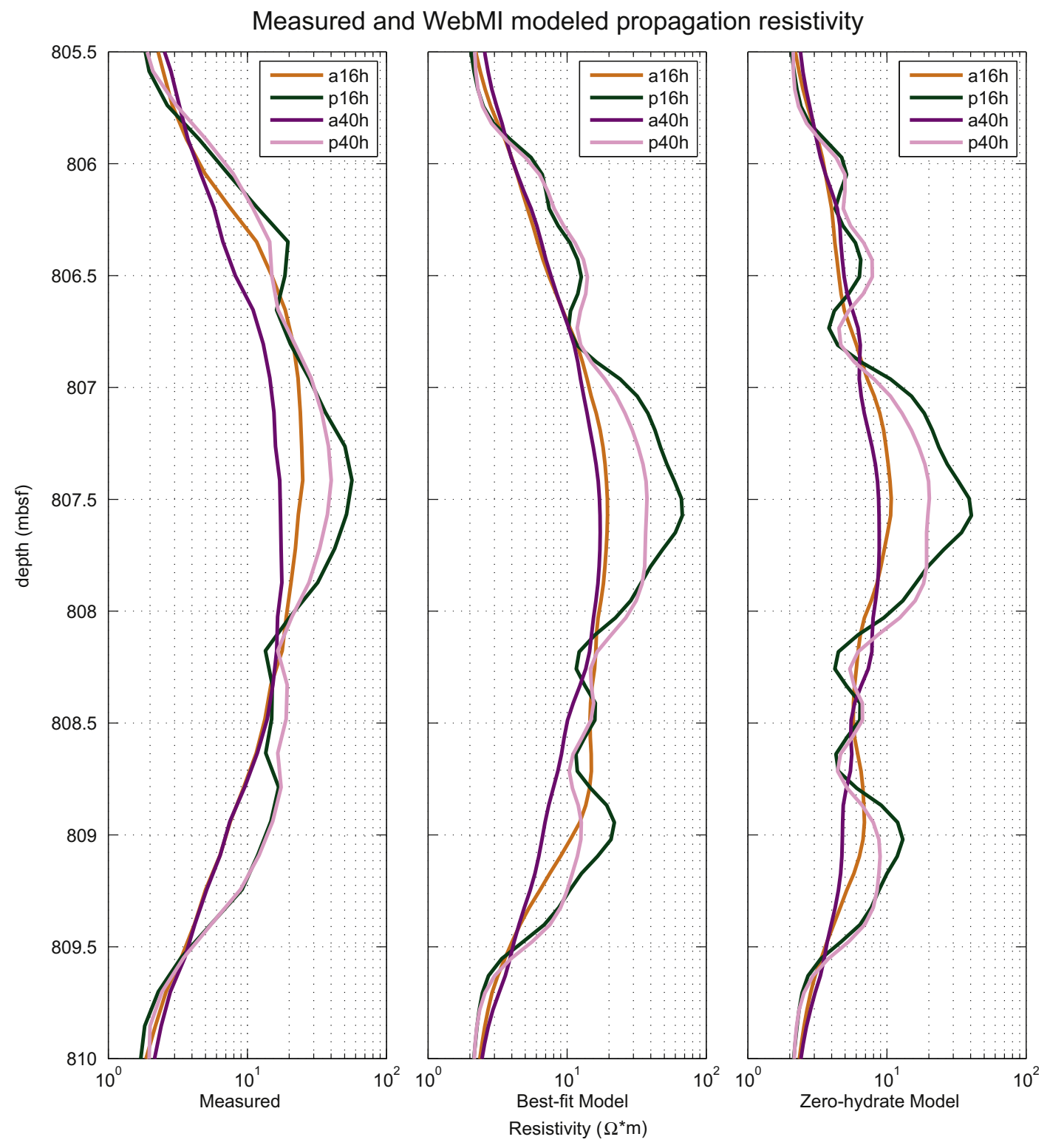

Figure 9. Measured propagation resistivity logs in comparison to logs generated for the best-fit model and zero-hydrate (control) model formations. 
shows these layers have a resistivity between 5 and $6 \Omega \mathrm{m}$, well above the expected resistivity of a water-saturated sand layer $(\sim 1.5 \Omega \mathrm{m})$ or the water-saturated clay sediment layer $(\sim 2 \Omega \mathrm{m}$ near $800 \mathrm{mbsf}$ ) in Hole WR313-H. This suggests that the lowresistivity layers almost certainly contain moderate saturations gas hydrate.

To further verify this result, we compare the best-fit formation model to a model without gas hydrate in the low-resistivity beds. We constructed a zero-hydrate formation model that replaces the resistivity values in the low-resistivity layers $(5 \Omega \mathrm{m})$ with the resistivity of water-saturated clay $(2 \Omega \mathrm{m})$. The zero-hydrate formation model and the ring resistivity generated from the control formation model are shown in Figure 7. In the yellow-highlighted layers, the zero-hydrate model generated logs have resistivity values between 2.0 and $3.3 \Omega$ m, much lower than the measured logs and generated best-fit $R_{\mathrm{t}}$ resistivity values, which range between 4.5 and $7.5 \Omega \mathrm{m}$. This further supports that the Hole WR313-H sand formation is composed of thin layers of sand sediment with varying hydrate saturations.

The top sand unit in Hole WR313-H has the highest resistivity values - some over $300 \Omega \mathrm{m}$ (Fig. 6). Thus, the more conductive layers in the top sand section in Hole WR313-H should exhibit the strongest effect from volume averaging or shoulder bed effects. In the zero-hydrate control model for Hole WR313-H (Fig. 9), the

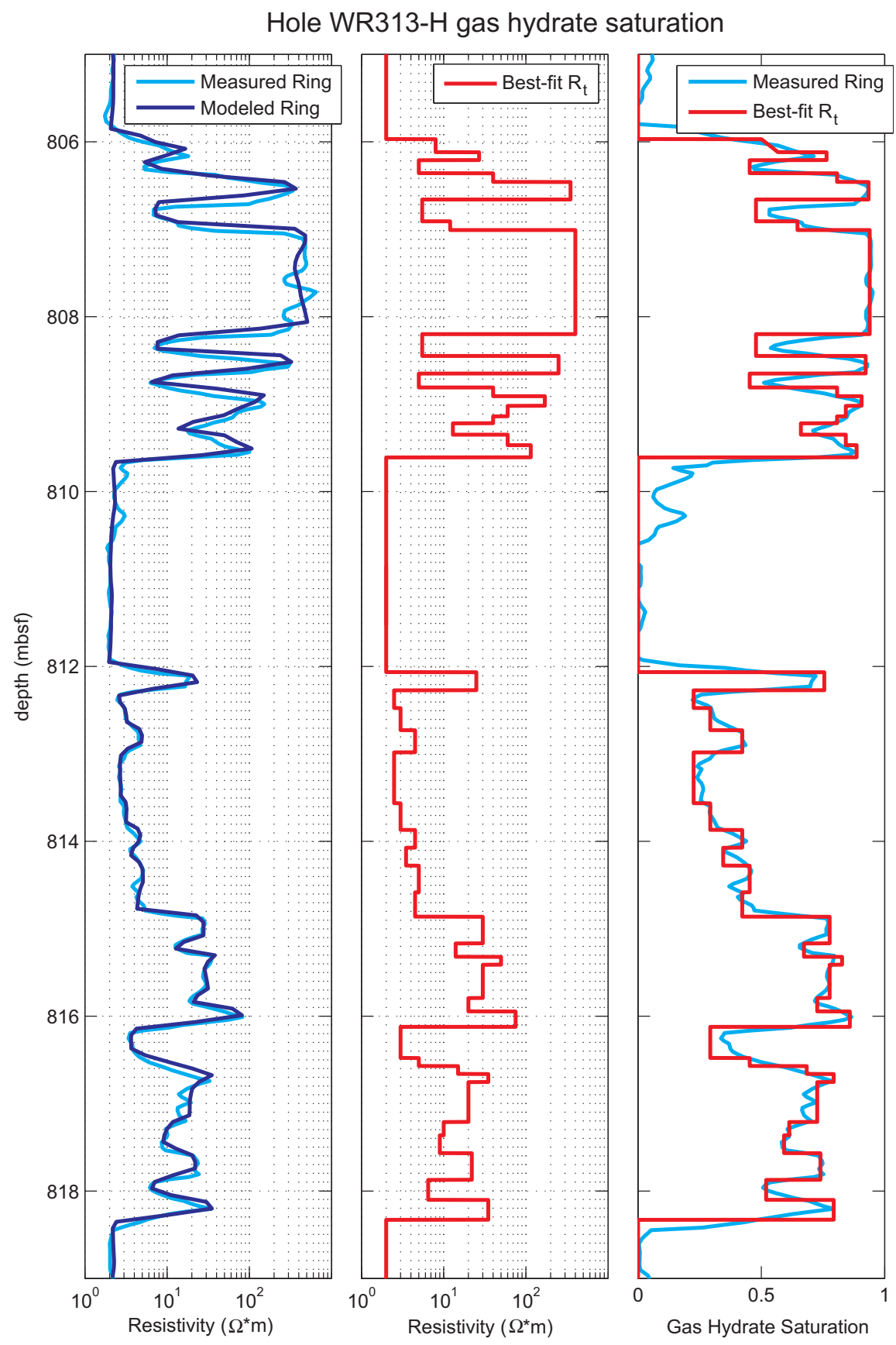

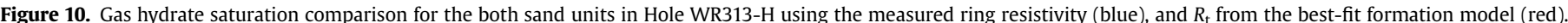

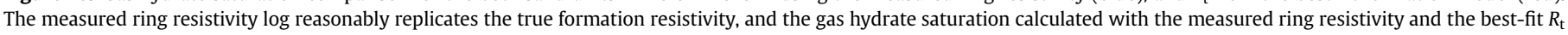
agree well. (For interpretation of the references to colour in this figure legend, the reader is referred to the web version of this article.) 
largest increase in ring resistivity in the yellow-highlighted layers due to volume averaging is a mere $1.3 \Omega \mathrm{m}$. The lower sand section in Hole WR313-H and all of the hydrate-bearing sand in Hole GC955-H, all have lower measured ring resistivity values than the top sand unit in Hole WR313-H (Figs. 2 and 6), and so, interbeds in these intervals are likely even less affected by volume averaging. Thus, in the hydrate-bearing sands in Hole WR313-H and GC955-H can be confidently interpreted to have interbedded thin layers of high and moderate gas hydrate saturation. Perhaps only beds with resistivity values near $2 \Omega \mathrm{m}$ are water-saturated, but even these beds may contain a small amount of gas hydrate in the pore space.

From looking at the results of Figure 7, one may question if changing the layer thickness and increasing or decreasing the layer resistivity may allow for a distinctly different best-fit $R_{\mathrm{t}}$. Layer thicknesses as well as the shape of the output ring resistivity $\log$ are important factors integrated into the best-fit model. To show this, we constructed a test formation model (Fig. 8) with and three different layer thickness of $9 \mathrm{~cm}, 13 \mathrm{~cm}$, and $25 \mathrm{~cm}$ with lowresistivity beds of $0.8 \Omega \mathrm{m}$ (Scenario A), $2 \Omega \mathrm{m}$ (Scenario B), and $5 \Omega \mathrm{m}$ (Scenario $\mathrm{C}$ ). The high-resistivity beds are all $30 \mathrm{~cm}$ thick and $100 \Omega \mathrm{m}$. The layer thicknesses were selected to represent the thinnest and thickest low-resistivity beds modeled in Hole WR313-H. In the resulting modeled ring resistivity logs, the thickest layer does not more accurately represent the prescribed $R_{\mathrm{t}}$ than the thinnest layer. For example, in Scenario B, where the formation model has $2 \Omega \mathrm{m}$ interbeds, the lowest resistivity values are: $2.55 \Omega \mathrm{m}$ (9 cm layer), $2.64 \Omega \mathrm{m}$ (13 cm layer), and $2.54 \Omega \mathrm{m}$ (25 cm layer). The very small differences between the lowest resistivity are likely due to the location of the layer in the formation model and not layer thickness. In addition, the $9 \mathrm{~cm}$ layer produces a significantly different shape than the $25 \mathrm{~cm}$ layer on the output ring resistivity log. Clearly, layer thickness and resistivity are both important components to determining the best-fit $R_{\mathrm{t}}$, and significantly different combinations of layer thickness and resistivity cannot be put together to achieve an $R_{\mathrm{t}}$ with an equivalent fit.

Propagation resistivity logs were also generated using WebMI to verify the results of the formation models. Figure 8 shows a selection of the measured propagation resistivity logs alongside the generated propagation resistivity logs for both the best-fit model and the zerohydrate model. The measured logs and best-fit model are very similar, in both in curve shape and resistivity values. The zero-hydrate model also shows a similar curve shape, but resistivity values are about an order of magnitude lower than the measured logs. The differences between the best-fit formation and zero-hydrate $R_{\mathrm{t}}$ are only a few $\Omega \mathrm{m}$ in the thin yellow-highlighted layers (Fig. 7, Track 2), yet, it has a strong influence on the generated propagation resistivity values, which are highly sensitive to the most conductive beds.

Figure 10 shows the best-fit $R_{t}$, as well as the measured and modeled ring resistivity logs for both sand intervals in Hole WR313$\mathrm{H}$. In comparison to the top sand interval, the lower sand interval has generally lower resistivity values for the best-fit $R_{\mathrm{t}}$ and more layers with gradational changes in resistivity. The last track in Figure 10 displays the calculated hydrate saturation over the top sand section in Hole WR313-H using the measured ring resistivity $\log$ and the best-fit $R_{\mathrm{t}}$. When high-resistivity layers surround a lowresistivity layer, the ring resistivity log overestimates the amount of gas hydrate typically between 5 and $10 \%$. In these low-resistivity layers, $R_{\mathrm{t}}$ produces the most accurate gas hydrate saturations, since $R_{\mathrm{t}}$ represents the formation resistivity with the tool response to volume averaging (shoulder beds) removed.

Overall, however, there is a good agreement between the ring resistivity and $R_{\mathrm{t}}$ gas hydrate saturation, suggesting again that the ring resistivity is a good approximation of the true resistivity in the JIP Leg II sand units.

\section{Conclusions}

In this paper we present $R_{\|}$and $R_{\perp}$ for gas hydrate-bearing sand reservoirs in Holes GC955-H, WR313-H and AC21-A from Gulf of Mexico JIP Leg II. $R_{\|}$and $R_{\perp}$ for each hole was obtained through a one-dimensional inversion of directional LWD resistivity data. In Hole AC21-A, we found the sand unit to be electrically isotropic. In contrast, in Holes WR313-H and GC955-H, the gas hydrate-bearing sand reservoirs are electrically anisotropic, with values of $R_{\|}$and $R_{\perp}$ differing by an order of magnitude.

We then further investigated the cause of the electrical anisotropy in the gas hydrate-bearing reservoirs. Our approach involved modeling the high-resolution ring resistivity log with WebMI, which yields more precise calculations of hydrate saturation and layer thickness than using the log apparent resistivities. We show that the hydrate-bearing sand units in Holes WR313-H and GC955$\mathrm{H}$ are composed of thin beds with fluctuating gas hydrate saturations. The thin beds are on the order of $10-100 \mathrm{~cm}$ thick with gas hydrate saturations ranging between 15 and $95 \%$. While the WebMI best-fit formation model yields the most accurate hydrate saturations, we find the ring resistivity log reasonably replicates the true formation resistivity in the sand reservoirs.

\section{Disclaimer}

This manuscript was prepared as an account of work sponsored by an agency of the United States Government. Neither the United States Government nor any agency thereof, nor any of their employees, makes any warranty, express or implied, or assumes any legal liability or responsibility for the accuracy, completeness, or usefulness of any information, apparatus, product, or process disclosed, or represents that its use would not infringe privately owned rights. Reference herein to any specific commercial product, process, or service by trade name, trademark, manufacturer, or otherwise does not necessarily constitute or imply its endorsement, recommendation, or favoring by the United States Government or any agency thereof. The views and opinions of authors expressed herein do not necessarily state or reflect those of the United States Government or any agency thereof.

\section{Acknowledgments}

We would like to thank the members, planners, co chiefs and participants of the Gulf of Mexico Gas Hydrate Joint Industry Project Leg II as well as Chevron and the US Department of Energy. The modeling for this paper would not have been possible without the collaboration of Schlumberger, and the use of their modeling software. This manuscript was improved by the helpful comments of $\mathrm{R}$. Boswell and an anonymous reviewer. This material is based upon work supported by the US Department of Energy, National Energy Technology Laboratory, while holding a National Research Council Research Associateship Award, under Award Number DEFC26-05NT42248.

\section{References}

Anderson, B., 1986. The analysis of some unsolved induction interpretation problems using computer modeling. Paper Presented at SPWLA 27th Annual Logging Symposium, Houston, TX, June 1986. Paper II.

Anderson, B., Barber, T.D., Singer, J., Broussard, T., 1989. ELMOD - putting electromagnetic modeling to work to improve resistivity log interpretation. Paper Presented at SWPLA 30th Annual Logging Symposium, Denver, CO, June 11-14, 1989. Paper M

Anderson, B.I., Bryant, I., Luling, M., Spise, B., Helbig, K., 1994. Oilfield anisotropy: its origins and electrical characteristics. Oilfield Review 6 (4), 48-56. 
Anderson, B.I., 2001. Modeling and inversion methods for the interpretation of resistivity logging tool response. Ph.D. dissertation, Delft University, The Netherlands.

Archie, G.E., 1942. The electrical resistivity log as an aid in determining some reservoir characteristics. Transactions of AIME 146, 54-63.

Boswell, R., Fyre, M., Shedd, W., McConnell, D., Shelander, D., in this volume-a. Architecture of gas-hydrate-bearing sand reservoirs, Walker Ridge 313, Green Canyon 955, and Alaminos Canyon 21, northern Gulf of Mexico. Journal of Marine and Petroleum Geology.

Boswell, R., Collett, T., Frye, M., Shedd, W., McConnell, D., Shelander, D., in this volume-b. Subsurface gas hydrates in the northern Gulf of Mexico. Journal of Marine and Petroleum Geology.

Clennell, M.B., Hovland, M., Booth, J.S., Henry, P., Winters, W.J., 1999. Formation of natural gas hydrates in marine sediments 1 . Conceptual model of gas hydrate growth conditioned by host sediment properties. Journal of Geophysical Research 104 (B10), 22985-23004. doi:10.1029/1999JB900175.

Collett, T.S., Ehlig-Economides, C.A., 1983. Detection and evaluation of the in-situ natural gas hydrates in the North Slope Region, Alaska. SPE California Regional Meeting, 23-25 March 1983, Ventura, California. Paper 11673-MS.

Collett, T.S., Ladd, J., 2000. Detection of gas hydrate with downhole logs and assessment of gas hydrate concentrations (saturations) and gas volumes on the Blake Ridge with electrical resistivity data. In: Paull, C.K., Matsumoto, R. Wallace, P.J., Dillon, W.P. (Eds.), Proceedings of the Ocean Drilling Program, Scientific Results Leg 164. Ocean Drilling Program, College Station, TX, pp. 179-191.

Collett, T.S., 2001. A review of well-log techniques used to assess gas-hydratebearing reservoirs, in natural gas hydrates: occurrence, distribution and detection. In: Paull, C.K., Dillion, W.P. (Eds.), American Geophysical Monograph, pp. 189-210.

Collett, T., Lee, M., Lewis, R., Mrozewski, S., Guerin, G., Goldberg, D., Cook, A., in this volume. Gulf of Mexico gas hydrate joint industry project leg II logging-whiledrilling data acquisition and displays. Journal of Marine and Petroleum Geology.

Ellis, D.V., Singer, J.M., 2007. Well Logging for Earth Scientists, second ed. Springer Dordrecht, The Netherlands.

Frye, M., Shedd, W., Godfriaux, P., Collett, T., Lee, M., Boswell, R., Dufrene, R. McConnell, D., 2010. Gulf of Mexico Gas Hydrate Joint Industry Project Leg II: Alaminos Canyon 21 Site Summary Available Online at: http://www.netl.doe. gov/technologies/oil-gas/futuresupply/methanehydrates/JIPLegII-IR/.

Hagiwara, T., 1997. "Macroscopic anisotropy" approach to analysis of thinly laminated sand/shale sequences: sensitivity analysis of sand resistivity estimate and environmental corrections. Paper Presented at the SPE Annual Technical Conference, San Antonio Texas, October 5-8, 1997. Paper 38669.

Hanor, J.S., Mercer, J.A., 2010. Spatial variations in the salinity of pore waters in the northern deep water Gulf of Mexico sediments: implications for pathways and mechanisms of solute transport. Geofluids $10(1-2), 83-93$. doi:10.1111/j.1468 8123.2009.00271.x

Hyndman, R.D., Yuan, T., Moran, K., 1999. The concentration of deep sea gas hydrates from downhole electrical resistivity logs and laboratory data. Earth and Planetary Science Letters 172 (1-2), 167-177. doi:10.1016/S0012-821X(99) 00192-2.

Kennedy, W.D., Herrick, D.C., Yao, T., 2001. Calculating water saturation in electrically anisotropic media. Petrophysics 42 (2), 118-136

Klein, J.D., Martin, P.R., Allen, D.F., 1997. The petrophysics of electrically anisotropic reservoirs. Petrophysics 38 (3), 25-36.

Kleinberg, R.L., Flaum, C., Griffin, D.D., Brewer, P.G., Malby, G.E., Peltzer, E.T. Yesinowski, J.P., 2003. Deep sea NMR: methane hydrate growth habit in porous media and its relationship to hydraulic permeability, deposit accumulation, and submarine slope stability. Journal of Geophysical Research 108 (2508) doi:10.1029/2003JB002389.

Lee, M., Collett, T., Lewis, K., in this volume. Anisotropic models to account of large borehole washout when estimating gas hydrate saturation at the AC21-B well, Gulf of Mexico. Journal of Marine and Petroleum Geology.

Li, Q., Omeragic, D., Chou, L., Yang, L., Duong, K., Smits, J., Yang, J., Lau, T., Liu, C.B. Dworak, R., Dreuillault, V., Ye, H., 2005. New directional electromagnetic tool for the proactive geosteering and accurate formation evaluation while drilling. Paper Presented at SWPLA 46th Annual Logging Symposium, New Orleans, LA, June 26-29, 2005. Paper UU.
Lüling, M.G., Rosthal, R.A., Shray, F., 1994. Processing and modeling 2-MHz resistivity tools in dipping, laminated, anisotropic formations. In: SPWLA 35th Annual Logging Symposium, Tulsa. Paper QQ.

Malinverno, A., Kastner, M., Torres, M.E., Wortmann, U.G., 2008. Gas hydrate occurrence from pore water chlorinity and downhole logs in a transect across the northern Cascadia margin (Integrated Ocean Drilling Program Expedition 311). Journal of Geophysical Research 113 (B8), B08103. doi:10.1029/2008JB005702.

McConnell, D.R., Kendall, B.A., 2003. Images of the base of gas hydrate stability in the deepwater Gulf of Mexico: examples of gas hydrate traps in northwestern Walker Ridge and implications for successful well planning. The Leading Edge 22 (4), 361-367.

McConnell, D., Zhang, Z., 2005. Using acoustic inversion to image buried gas hydrate distribution. In: Fire in the Ice, Methane Hydrate Newsletter. US Department of Energy Fall 2005.

McConnell, D., Boswell, R., Collett, T., Frye, M., Shedd, W., Guerin, G., Cook, A., Mrozewski, S., Dufrene, R., Godfriaux, P., 2010a. Gulf of Mexico Gas Hydrate Joint Industry Project Leg II: Green Canyon 955 Site Summary Available Online at: http://www.netl.doe.gov/technologies/oil-gas/futuresupply/methanehydrates/ JIPLegII-IR/.

McConnell, D., Boswell, R., Collett, T., Frye, M., Shedd, W., Guerin, G., Cook, A. Mrozewski, S., Dufrene, R., Godfriaux, P., 2010b. Gulf of Mexico Gas Hydrate Joint Industry Project Leg II: Walker Ridge 313 Site Summary Available Online at: http://www.netl.doe.gov/technologies/oil-gas/futuresupply/methanehydrates/ JIPLegII-IR/.

Mrozewski, S., Guerin, G., Cook, A., Collett, T., Boswell, R., 2010. Gulf of Mexico Joint Industry Project Leg II: LWD Methods Available Online at: http://www.netl.doe. gov/technologies/oil-gas/futuresupply/methanehydrates/JIPLegII-IR/.

Nimblett, J., Ruppel, C., 2003. Permeability evolution during the formation of gas hydrates in marine sediments. Journal of Geophysical Research 108 (B9), 2420. doi:10.1029/2001JB001650.

Pearson, C.F., Halleck, P.M., McGuire, P.L., Hermes, R., Mathews, M., 1983. Natural gas hydrate deposits: a review of in situ properties. The Journal of Physical Chemistry 87 (21), 4180-4185. doi:10.1021/j100244a041.

Pearson, C.F., Murphy, J., Hermes, R., 1986. Acoustic and resistivity measurements on rock samples containing tetrahydrofuran hydrates: laboratory analogues to natural gas hydrate deposits. Journal of Geophysical Research 91 (B14), 14132-14138. doi:10.1029/JB091iB14p14132.

Polyakov, V., Habashy, T., Kocian, R., Pabon, J., Anderson, B., 2004. Interactive log simulation and inversion on the web. Paper Presented at the SPE Annual Technical Conference, in Houston, TX. Paper 90900-MS.

Polyakov, V., Kocian, R., Omeragic, D., Habashy, T., 2007. Modeling and inversion of geophysical well logging tool responses in a service-oriented high performance computing architecture. Paper Presented at the IEEE International Conference on Web Services. Salt Lake City, Utah, USA. Paper 9869164.

Polyakov, V., Kocian, R., Omeragic, D., Habashy, T., 2009. Distributed highperformance computing framework for modeling and inversion of geophysical well logs. In: Topping, B.H.V., Ivdnyi, P. (Eds.), Proceedings of the First International Conference on Parallel, Distributed and Grid Computing for Engineering. doi:10.4203/ccp.9A.26 Stirlingshire, UK, Paper 26, 2 AO9.

Santamarina, J.C., Ruppel, C., 2008. The impact of hydrate saturation on the mechanical, electrical, and thermal properties of hydrate bearing sands, silts and clay. In: Englezos, P. (Ed.), Paper Presented at the 6th International Conference on Gas Hydrates Available Online at: https://circle.ubc.ca/handle/ 2429/2325 Vancouver, Canada.

Schlumberger, 2006. geoVISION: Resistivity Image-While-Drilling Service. Schlumberger.

Seol, Y., Kneafsey, T.J., 2009. X-ray computed-tomography observations of water flow through anisotropic methane hydrate-bearing sand. Journal of Petroleum Science and Engineering 66 (3-4), 121-132. doi:10.1016/ j.petrol.2009.01.008.

Spangenberg, E., 2001. Modeling of the influence of gas hydrate content on the electrical properties of porous sediments. Journal of Geophysical Research. 106 (B4), 6535-6548. r2000JB90043.

Sun, K., Omeragic, D., Cao Minh, C., Rasmus, J., Yang, J., Davydychev, A., Habashy, T., Griffiths, R., Reaper, G., Li, Q., 2010. Evaluation of resistivity anisotropy and formation dip from directional electromagnetic tools while drilling. Paper Presented at SPWLA 51st Annual Logging Symposium, June 19-23, 2010, Perth, Australia. Paper I. 